\title{
TQM in Small and Big Organizations
}

\author{
Enaam Faihan Mofreh Alotaibi ${ }^{1}$, Dania Mahmoud Ghalib Bahssas ${ }^{2}$, Syed Hamid \\ Hasan $^{3}$ \\ 1,2,3 Faculty of Computing and Information Technology, \\ Department of Information Systems \\ King Abdulaziz University, Kingdom of Saudi Arabia \\ shhasan@kau.edu.sa
}

\begin{abstract}
An organization's flexibility, effectiveness and competitiveness can be improved through TQM. We can find a number of organization who have utilized TQM in order to achieve growth and cost effectiveness, we can also find some business that have not been so successful in realizing the benefit of TQM. There has been ample research done on the reason of the failure of TQM implementation in organizations and some of the reason for failure are quoted as: low employee involvement; no support from senior management and scarcity of resources. Whereas there are a number of other factors that have been covered by very few researchers, like lack of proper communication and handling of the transformation brought in the organization, improper training and awareness methods; that lead to failure of TQM in any organization. There were a number of studies done for evaluating the process of successful implementation of TQM in SMB manufacturing companies and this paper would cover such an exercise performed in three small companies. The areas where the implementation bought improvement were Administrative Procedures, Product Quality, Cost effectiveness and employee motivation, and the aspects that were still found to be weak were team building, continual improvement in quality and technical training.
\end{abstract}

Keywords - Organization, Education, Training, Competitiveness, TQM \& SMB

\section{Council for Innovative Research}

Peer Review Research Publishing System

Journal: International Journal of Management \& Information Technology

Vol. 9, No. 3

editor@cirworld.com

www.cirworld.com, member.cirworld.com 


\section{INTRODUCTION}

However, we have known TQM to be an approach employed by multinational companies in achieving high levels of organizational improvement \& customer satisfaction [1,2]. We even have a wide number of researchers that support the idea of TQM being an effective management strategy which can bring an improvement in the management's capabilities to achieve goals, strategy \& targets of an organization [1] if proper planning and implementation is done [3]. Continual improvement, better team work and worker empowerment are also the results of TQM [4]. Some of the research work done in the field of Total Quality Management indicate that there has been a high failure rate in the implementation of TQM in different companies, some of them pegging it as high as $60 \% \& 67 \%$, if we believe this data TQM has not been a reliable option for business [5]. According to the published research works TQM has been utilized by a number of organizations successfully, even though we have a published success rate of $33-40 \%$. The numbers are in tandem with the idea that failure of the implementation is not necessarily the result of the TQM principles but it would most likely be caused by the other factors like ignoring of the impact of the TQM implementation hindrances in an organization and the underlying dynamic cultural factor. The following study was inspired by the same idea.

TQM implementation can bring about a transformation in an organization [6]. The attitude and the working behavior can be impacted by effective training, support from the top management and free channels of communication. [1, 8]. However, an atmosphere of mistrust and employee demotivation may result if the process of implementation is not planned and executed effectively [7,2]. On the other hand where the planning is proper with proper strategy for educating the people and training does not lack resources TQM has been successful implemented by a number of organizations [7].

With the help of proper communication, commitment from the senior management and effective training, the workers can be left to concentrate on Quality [9] making TQM implementation smooth. Fig 1 shows the factors critical for the implementation of TQM. Some of factors commonly demarked as performance improvers are; continuous improvement, Supplier partnership, decisions based on facts, open culture, employee involvement, management leadership, customer focus and quality efforts. [2,4,10]. The paper studies the efforts of 3 SMB manufacturing companies in Quality training, communication of TQM philosophy and the strategies they adopted in making the most of a TQM implementation. The 3 companies used the ISO 9000:2008 platform as a basis of implementing TQM, even though they have not attempted the ISO Certification. Despite the common base the implementation methodology were unique owing to individual Cultures, leadership styles and organizational structure $[11,12]$.

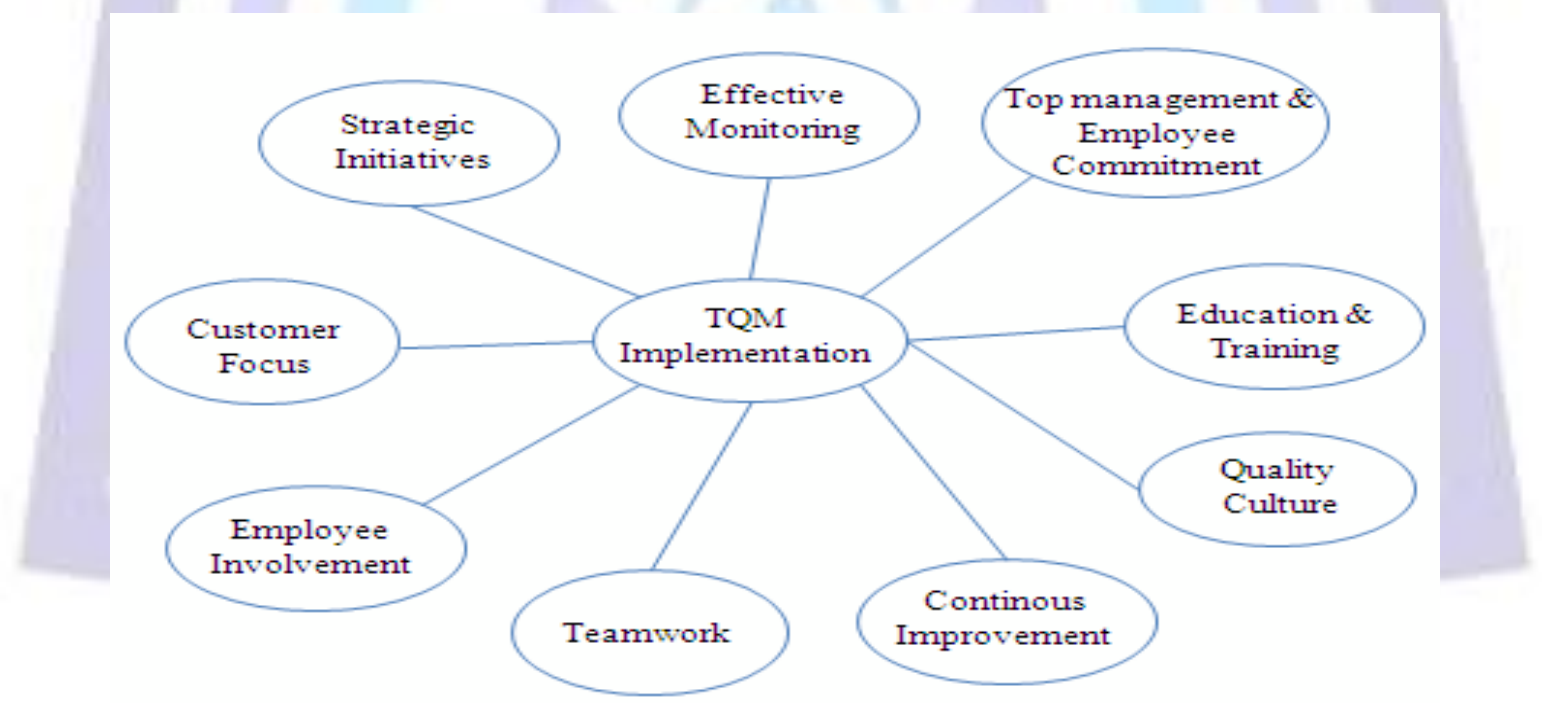

Fig. 1 TQM implementation - Critical factors for

\section{CASE STUDY BACKGROUND}

\section{Company $A$}

In the first case study a company that manufactures Agricultural equipment was covered. The company has its own foundry where it casts equipment like Ploughs, Harrows and which are both tractor drawn as well as Ox-drawn. It also has a part working on service and assembly of tractors.

\section{Company $B$}

The second company was also into manufacturing various products like ball mills, pipe joints, water reticulation and sewer pipes, pump bodies and valves. It also manufactures some agricultural equipment as well.

\section{Company $C$}

The third manufacturing company was plastics, it dealt with extrusion and casting of Plastic parts used both by the 
industry as well as domestic sector some part of the business was electronic gadgets manufacturing.

All the three companies were under the Small and Medium Business (SMB) category that implemented TQM to effectively improve business.

\section{OBJECTIVES OF THE RESEARCH}

a) In this paper we will study the communication \& Training aspects of the TQM implementation that the 3 companies experienced between $2008-2012$.

b) We also study the monitoring process of the TQM in these companies in the same period.

\section{RELATED RESEARCH}

\section{1. $T Q M$}

We can define TQM as the principals that guide the philosophy of working with the employees to bring about change in an organization [1,3]. It is also the process of managing the entire business to achieve and exceed customer satisfaction at possibly both external and internal levels. [2,6]. The methodology of process improvement as suggested by TQM enables organizations to obtain the goals of continual improvement and even significant breakthroughs in the process gains. The purpose of TQM implementation for some companies is achieving customer satisfaction, increasing productivity and surpass competition. [4, 15]. Factors such as communication, team work, continual improvement and leadership are covered by TQM [13]. Companies that have implemented TQM employ process management techniques to develop cost effective and stable processes that enable them in achieving customer satisfaction [14].

\section{Transforming Organizations}

The process of implementation, of TQM is dynamic [1] and it results in transformation of organizations [8]. A number of factors need to be monitored in order to reduce the apprehensions and reservations of the employees and to bring about a cultural change during the implementation of TQM [16].

"The authors in $[17,18,19]$ have divided the changes that occur in TQM Implementation into 4 types i.e. Changes in Power sharing; Human behavior, beliefs and values; organization structure and processes in the organizations. However we are going to study all the types in totality rather than treating them as individual traits. All the employees must be empowered by the senior management while taking complete responsibility of the nurturing and implementing the TQM activities for a successful transformation [18].

Concepts of Teamwork and quality must be committed to by the employees for bringing a cultural change as emphasized by TQM. While values and norms that aim at quick fixes and short term gains [15] and giving priority to the department aims over the organizational goals [19] are hindrances to the culture change sought by TQM. Performance management systems based on teams rather than individuals are encouraged by the TQM philosophy [20]. However favoring of a specific team for providing of resources[21] and resultant worker's mistrust [15] caused by organizational politics is not dealt by TQM.

\section{Effective Training}

While contributing to the achievement of the organizational goals and objectives the subordinates are helped by training for understanding their accountability, authority and responsibilities [22]. Training is aimed at imparting new and attitudes, skills and knowledge (KSA) to the employees in order to bring improvement in performance [22]. "In [23]the author argues that enhancement of training can be achieved by applying KSA in fields such as job design, individual motivation, supervisor feedback, coaching, peer support, workload and goal setting. All modern day organizations believe in enhancing their capability by building up infrastructure that nurture the information sharing and continuous learning culture [24] and this kind of setup greatly supports implementation of TQM [1]

The training is aimed at enabling the employees to adjust to the ever changing environment of competition globally, as this one of the capability that gives the organizations the leading edge [25]. The other features that enables the organizations to excel are effective learning and knowledge management at the organizational level [26], the author in [27] supports the claim above and reports that an organizationa's knowledge and learning capabilities can give it a competitive edge. The influence the imparted training can be assessed through both intangible and tangible factors [28]. The improvement in employee self-esteem and motivation are the intangible factors while reduction in errors and improvement in quality results are the tangible factors [28].

\section{Effective communication}

The term communication can be defined as a transmission relevant information. In an organization, communications occur at 3 major levels: Organizational, Interpersonal and Intrapersonal [21]. Referential to this study is process of systematic gathering, analysis and communication of data for solving of issues related to Quality by an organization. This process is commonly known as QMI (Quality Management Information) [29].

A broad data range is provided by QMI from suppliers, customers, design, manufacturing, marketing and purchasing. [30]. Other means of enhancing inter department communication are use of software systems like ERP (Enterprise Resource Planning) and Intranet. EPM(Enterprise Performance Management) along with Intranets help 
the management and employees in effective communication of organizational strategies thus resulting in a better understanding of the same [31]. Information form CRM and ERP systems is collected by EPM.

\section{APPROACH FOR RESEARCH}

The steps for carrying out the research included reviewing of relevant literature and an extensive case study covering 5 SMB engineering firms. In [32] it is stated that the case studies are a means of comparing, explaining, describing and exploring and [33] argues that case study is a method of focusing on one entity's processes and relationships in an natural environment where we have the options of using multiple methods and sources for analysis and data gathering. As suggested in [34] the triangulation methodology was employed for data collection, which included detailed interviews, an elaborate questionnaire used for a survey and comprehensive review of relevant research works. The focus of the questionnaire was progress monitoring, communication, education and training for TQM so that it would cover reworks, scraps, productivity level and product quality.

\section{FINDINGS OF THE RESEARCH}

Out of the total population surveyed 47 respondents were received from the survey, 15 for company $\mathrm{A}, 16$ for company $\mathrm{B}$ and 16 for company $\mathrm{C}$. We would be analyzing the response of the survey in the following section.

\section{A. Training Type}

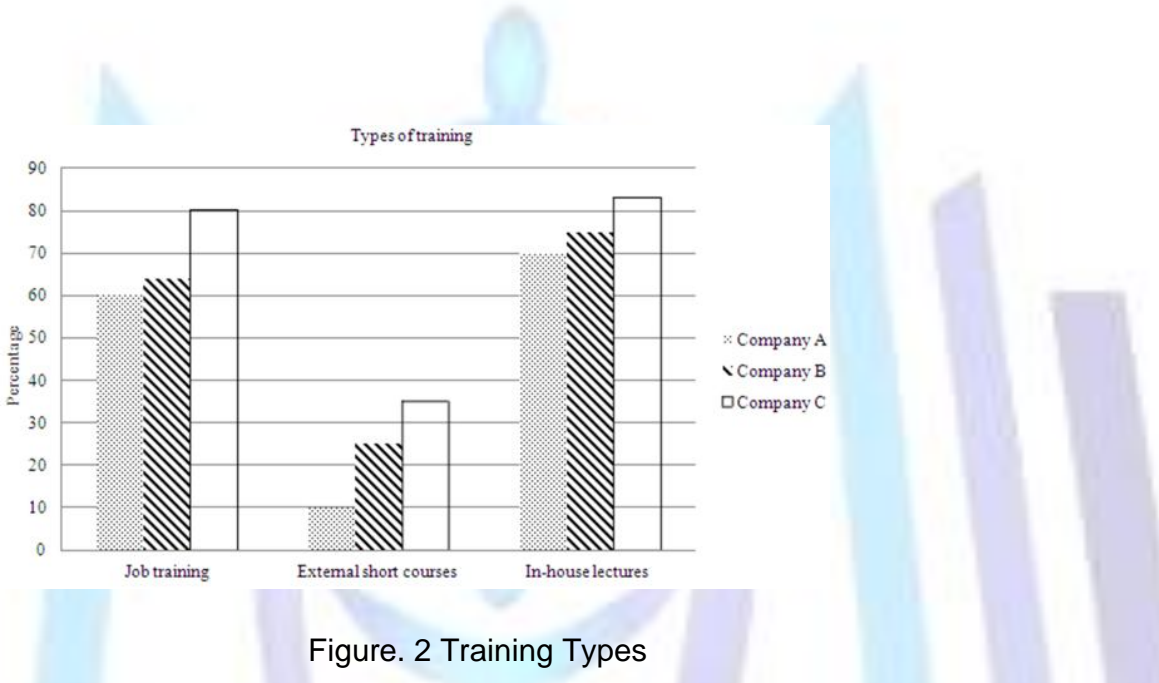

The in-house lectures, short external courses and on the job training [6] methods were used training the staff. The training format was various session by both Managers/ Supervisors in the form of meetings and external trainers in the form of short courses [35] organized by the company. Quality improvement can be achieved through proper training [36]. Improvement was observed in areas like leadership and teamwork skill for the supervisors as a result of the training [9].

\section{B. Soft Skills Training}

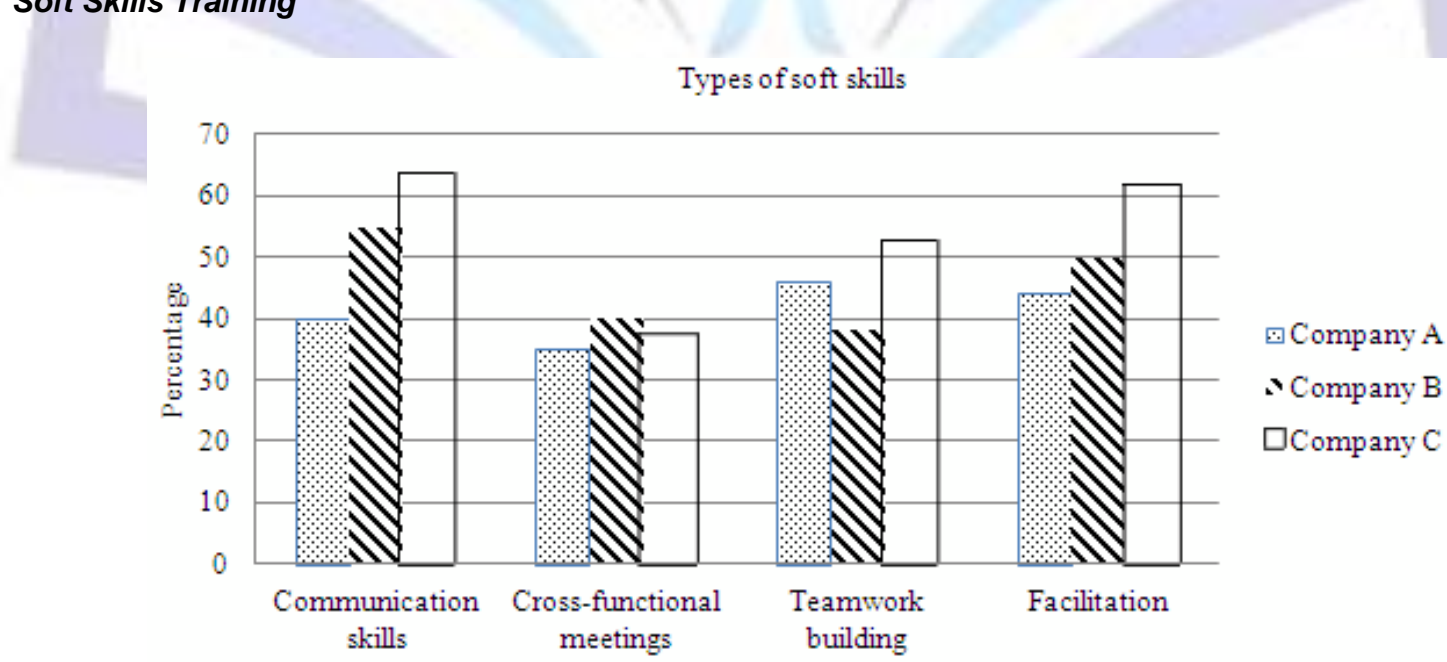

Fig. 3 Summary of soft skills training

In comparison to company $A$ \& $B$, company $C$ fared much better in organizing soft skills training for facilitation, teamwork building and communication skills. An essential part of quality improvement process is the improvement in Soft skills [6, 36]. For company B it was observed that focus was on ensuring effective communication from the manager/supervisors to their subordinates on both informal and formal levels [37] this communication was inclusive 
of getting reviews from them about company performance and answering any queries that the employees may have [37]. There were monthly team meetings which were open to ask questions and seek clarifications and this approach supported the implementation of TQM as presented by [36, 38]. These Queries and their answers were made public through notice boards. Top managers visited the production lines on a regular basis and anything relevant was discussed freely with the employees [35]. Suggestions were welcomed and anything feasible was supported, while clear explanation of ideas that could not be implemented were provided. For company A also there were meetings where ideas were shared along with the question answer sessions. But the level of consultation and participation in strategy building was not as great as the other companies till the time the study was conducted.

In the first phases of the implementation, training was provided related to all practical aspects of TQM. The training covered problem solving approach and TQM tools like np-charts \& p-charts, Scatter Digrams \& Pareto digrams, histograms, Cause \& Effect diagram and brainstorming session. The data is displayed in fig 4. Collection, analysis and sharing of the Quality performance indicators like rework, Scrap and defect rate showed that they were improved upon by company A \& B along with improvement in process management. This was in sync with [39] where it was proved that Quality improvement can be achieved by utilizing the quality metrics collected from reliable sources.

\section{Training in Statistical Quality Tools}

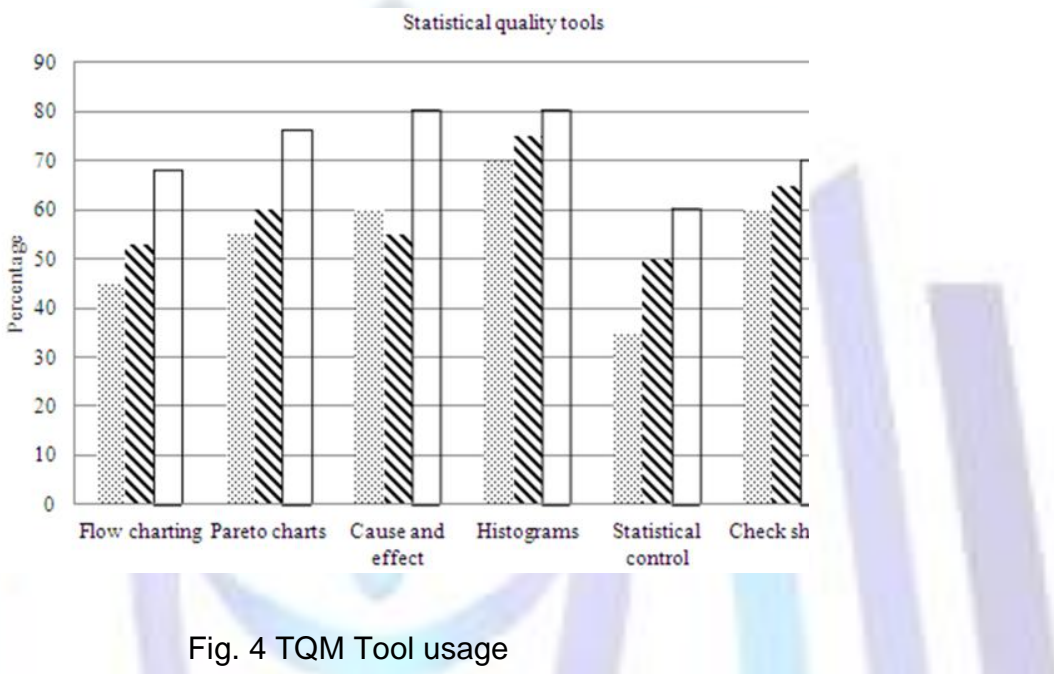

It was observed that there was a visible commitment from Company $\mathrm{C}$ related to effective training that was also available in company B. Company A however lacked in performance and it was demonstrated by the research that one of the responsible factors was allocation of insufficient resources for training by the management. The factors hindering effective training were high labor attrition, expensive consultation fees by experts in quality, low awareness levels on quality in the company, feeble structure of project management and lack of resource, which also hampered the organization's efforts of maintaining quality levels.

For all the studies organizations the training covered process improvement, improvement teams, QMS(Quality Management System), commitment and understanding, however advance methods of quantitative analysis were not covered[11]. Obstacles encountered in all the cases were senior management's negative attitude regarding the training of the employees [40] while interacting with them most of the managers expressed need for investment in business survival tactics instead of investing in employee nurturing [41]. This sort of an attitude negatively affects the capability of the staff in achieving any major improvements [41] which can cause the company to achieve a competitive edge. Owing to lack of resources, the training did not cover advance quality concepts of QFD (Quality Function Deployment), Six Sigma and Design of Experiment.

\section{TQM Monitoring}

A TQM monitoring record was maintained by all the studies organizations and it showed improvement brought in the companies by TQM. The graphs below depict these factors. 


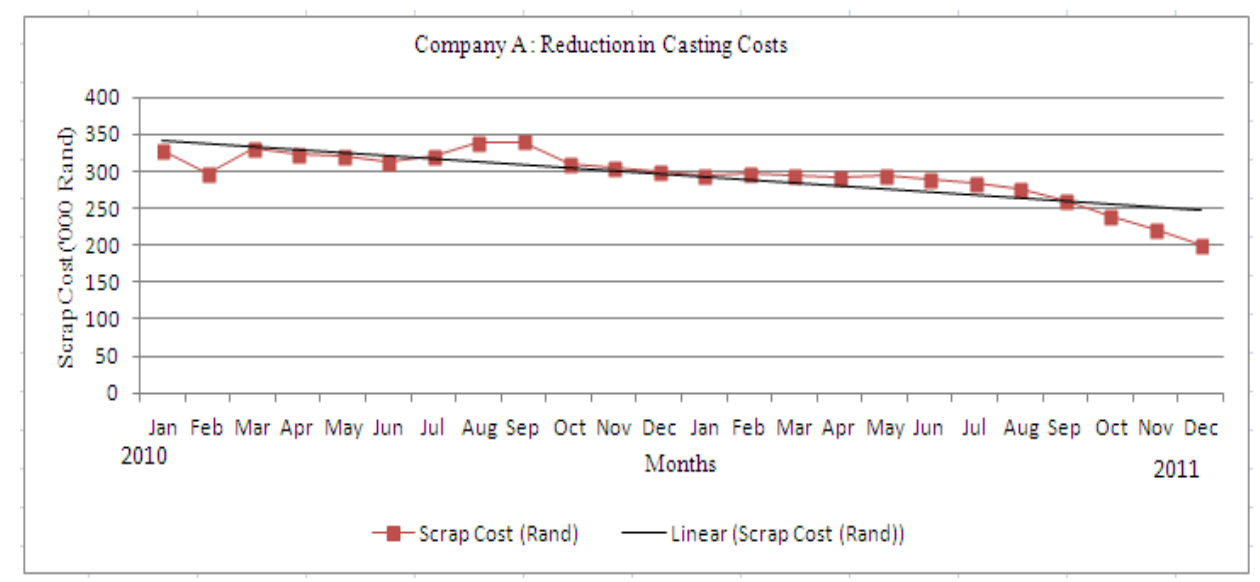

Fig. 5 Casting Costs reduction - Company A

Data related to cost of casting was collected for the period 2010-2011 and it was observed that there was a reduction in the cost after TQM implementation [42]. The cost include cost of energy, material and labor. The major reason for the reduction was the improvement in working methodology [9] as a result of improved resource utilization, reduced overtime and TQM training.

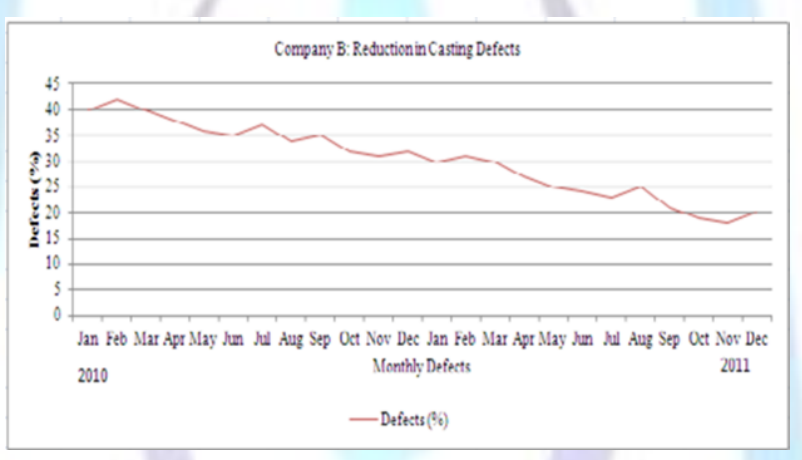

Fig. 6 Casting Defects Reduction- Company B

The data from the foundry of company B was analyzed with respect to defects in casting for 2010-2011 and a noticeable difference in the defects post TQM implementation. The foundry experienced cost reduction owing to less scrap and reworks. It in turn improved employee morale as the number of NCR(Non-Conformance Reports) were reduced. An important part was played by Employee involvement [16] for rectifying and identifying issues that caused the high rates of defects.

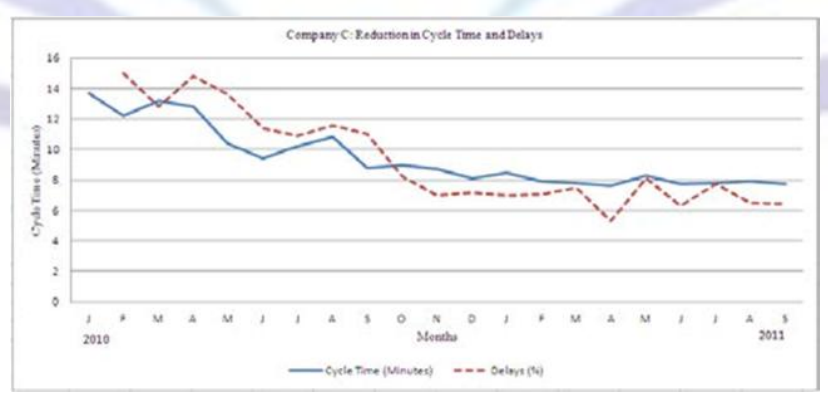

Fig. 7 Delay and Cyclic Times Reduction - Company C

For company $\mathrm{C}$ the collected data showed reduction in delays and cyclic times at the foundry. It was caused by the combined problem solving efforts by both the employees and the management [16], which clearly establishes the advantages of employee participation in TQM[1].

\section{E. Makeover of Organizations}

The ongoing process of Organizational makeover [15] cannot be attained in a short span [18]. For all the studied organization the makeover was led trained supervisors in quality improvement, experienced first line managers and facilitators. In company B \& C the facilitators were only acting as experts in quality [2] and were not part of production [15]. The responsibility of these facilitators was to oversee the training \& education and kick starting TQM 
[4]. TQM was being perceived an agent to bring about change [16] while the focus area improvement of the culture of quality improvement [1]. Yet some of the supervisors were not too pleased to be substituted by team leaders who were also part of the workforce [25]. The approach of substituting the supervisors was adopted to highlight the importance of the Team work [15] in day to day problem solving [3]. In totality successful implementation of TQM requires approximately 2-3 years before which clear results cannot be expected.

\section{F. Summary}

It is clearly demonstrated by all the studies companies that for a TQM implementation to be successful the role of Management in carrying out Training [43] ensuring effective communication[21] and people [16] is important. The benefits of TQM improvement in organizational commitment, better communication and increased employee motivation. [17]. In all the cases managers understood the importance of Teamwork, Continual improvement and customer focus $[2,13,18]$. All the three businesses lacked the concept continual process improvement $[2,4,10]$. The training methodology need to be improved for enhancing process standardization [35] and achieving breakthrough improvements in process [30]. Teams were found to not have reached the stage self assignment of tasks. Supervisors lacked flexibility of delegating the team members with accountability, authority and responsibility [9]. Even though this approach weakens the problem solving and decision-making capability of the employees [4].

It was observed during the research that limited training on customer focus was provided and that too lacked involvement of the customers. The interview data showed the teamwork was not voluntary but because of conscription and it is known to hamper employee creativity [14]. There was a major lacking of Cross functional meeting in all cases, one of the possible reason cited was lack of time. Also the other hindrances observed were the overall lack of allocated resources for TQM development [8], trouble in changing attitudes \& behavior, and inter departmental barriers [2]

\section{CONCLUSION}

One of the toughest part of the TQM implementation is bringing in of the culture of quality as this effort must be supported and participated by all levels of the company. The sturdy management structure advised by [47] were not found present and it weakened the efforts on building a solid team. Implementing of the quality culture can only be done if it has the unequivocal support of the top management. The same level of commitment is required from all ranks in the organization, even the worker's Unions, in establishing teamwork, employee empowerment and training $[7,9]$. The process of training and education is a ongoing process for making everyone comprehend the value of quality. The training of the quality teams is also necessary so that they are able to utilize the quality techniques and tools. The people in the TQM facilitator role should also take into account that any problem or change in the organization affects its social system. A collective behavioral change is required to being any changes as all the employees are involved in this process [4].

The Senior management, team leaders and team members of the quality team must take the lead in developing of the quality culture to achieve the end results. Last but not the least the organizational structure must also support quality framework e.g. we cannot have TQM in a military organization. The principles of TQM are still under development and its successful implementation mandates effective management, powerful administrative structure and a stable financial base.

\section{REFERENCES}

[1] J.S. Oakland, "Total Quality Management", 1998.

[2] M. Abdolshah, and S. Abdolshah, "Barriers to the successful implentation of TQM in Iranian manufacturing organisations", 2011.

[3] P. Thareja, D.D. Sharma and P.B. Mahapatra, "Total Quality Management-A Development Perspective" 2011.

[4] P.T. Thorton, "The Power of Vision: Total Qulaity Management Awareness", 1992.

[5] G. Taguchi, S. Chowdhry and Y. Wu, "Taguchi Quality Engineering Handbook," 2005

[6] A. Patel, "Assessing Total Quality Training in Wales", 1994.

[7] J.J. Tari, "Components of Successful total quality management" 1996.

[8] J.Almaraz, "Quality Management and the Process of Change" 1994.

[9] J.G. Motwani, L.M. Frahm and Y. Kathawala, "Achieving a Competitive Advantage through Quality Training" 1994.

[10] R. Kumar, D. Garg and T.K. Garg, T.K., "TQM success factors in North Indian manufacturing and service inductries", 2011.

[11] T.Cocheu, "Training with Quality", 1992

[12] P.W. Bowen, "The need for quality cultures" 1996

[13] M. Duffin, "Guidelines to TQC", 1995.

[14] B.Clegg, C. Rees and M. Titchen, "A study into the effectiveness of quality management training: A focus on tools and critical success factors" 2010.

[15] G. Cao, S. Clarke, S and B. Lehaney, "A systemic view of organisational change and TQM", 2000.

[16] P.W. Bowen, "The need for quality cultures", 1996.

[17] M. Kivimaki, E. Maki, K. Lindstrom, A. Alanko, S. Seitsonen and K.Jarinen, "Does the implementation of total quality management (TQM) change the wellbeing and work related attitudes of health care personnel? Study of a TQM Prize Winning Surgical Clinic", 1997. 
[18] G. Cao and B. Lehaney, "Towards sytematic management of diversity in organisational change", 1999.

[19] R.L. Flood, R.L., "Solving Problem" 1996.

[20] J. Schalkwyk, "Total quality management and the performance measurement barrier" 1998.

[21] M.C.Jackson, "Beyond the fads: systems thinking for managers", 1995.

[22] C. Holladay and M. Quinones, "Practice variability and transfer of training: the role of self-efficacy generality" 2003.

[23] L. Burke and H. Hutchins, "Training transfer: an integrative literature review", 2007

[24] N. Wickramasinghe, N. "Fostering knowledge assets in healthcare with the KMI model", 2007.

[25] M. Harvey, M.M. Novicevic, and G. Garrison, "Challenges to stafffing global virtual teams", 2004.

[26] G.N. Theriou and P.D. Chatzoglou, "Enhancing performance through best HRM practices, organisational learning and knowledge management: a conceptual framework", 2008.

[27] Y.C. Lee and S.K. Lee, "Capability, processes, and performance of knowledge management: a structural appproach", 2007.

[28] R.P. Griffin, "Workplace learning evaluation: a coneptual model and framework", 2011.

[29] M.J. Schniederjans, M.M. Parast, M..Nabavi, S.S. Rao and T.S. Raghu- Nathan, "Comparative analysis of Malcolm Baldridge National Quality Award criteria: an empirical study of India, Mexico and the United States", 2006.

[30] P. C. Anh and Y. Matsui.2011, "Relationship between quality management informantion and operational performance: International perspective", 2011.

[31] D.K. Denton, "Performance measurement and intranets: a natural partnership". 2010.

[32] R.K. Yin, "Case study research: Design and methods" 2003.

[33] M. Denscombe, "The Good Research Guide for small-scale social research projects", 2003.

[34] T.A. Scandura and E.A.Williams, "Mentoring and transformational leadership:the role of supervisor career mentoring". 2004.

[35] M.E. Spiess, "Finding Time for TQM Training", 1993.

[36] M. Kaeter, "Quality Training", 1991.

[37] M. Zairi, "Total quality education for superior performance", 1995.

[38] E. Davies, "A culture of satisfaction", 1997.

[39] X. Zu, L. Fredenhall and T.J. Douglas, "The evolving theory of quality management: the role of Six Sigma", 2008.

[40] H. Matlay, "Vocational education and training in Britain: a small business perspective", 1999.

[41] A. Panagiotakopoulos, "Barriers to employee training and learning in small and medium-sized enterprises", 2011.

[42] J.H Zenger, "Leadership Skills for Quality Improvement", 1989.

[43] J.V. Chelson, "Total quality through empowered training", 1997.

[44] P.J. Smit and G.J.D.E.Cronje, "Management Principles: A contemporary edition for Africa", 1997.

[45] S.D. Lapan and Q. T. Marylynn T. "Research Essentials:An Introduction to Designs and Practices Research Methods for the Social Sciences". 2009.

[46] A.G.Woodside, "Case Study Research", 2010.

[47] R. Beckhard and W. Pritchard, "The Art of Creating and Leading Fundamental Change in Organistions", 1992. 